\title{
DETAILED AIRBORNE GEOPHYSICAL SURVEY OF COMPLEXLY DISLOCATED STRATA IN THE SUTAM TERRANE (ALDAN SHIELD) DURING STUDIES OF IRON-ORE DEPOSITS
}

\author{
A.A. Syasko $^{1}$, N.N. Grib ${ }^{2}$, V.S. Imaev ${ }^{3}$, L.P. Imaeva ${ }^{3}$, I.I. Kolodeznikov ${ }^{4}$
}

${ }^{1}$ LLC Neryungri Geophysics, Neryungri, Russia

${ }^{2}$ Technical Institute (branch) of M.K. Ammosov North-Eastern Federal University, Neryungri, Russia

${ }^{3}$ Institute of the Earth's Crust, Siberian Branch of RAS, Irkutsk, Russia

${ }^{4}$ Academy of Sciences of the Republic of Sakha (Yakutia), Yakutsk, Russia

\begin{abstract}
Magnetic exploration is the most informational and economical method of prospecting and exploration of iron-ore deposits. In rough-terrain and remote areas without any infrastructure, problems associated with groundbased methods can be avoided by using modern unmanned technologies that allow conducting geophysical surveys in a more efficient way. An unmanned aeromagnetic survey complex (aerial vehicle, UAV) Geoscan 401 was used to assess the possibility of using UAVs for aeromagnetic surveying of iron-ore deposits. Our experimental study was conducted in the well-studied area of the largest iron-ore deposit of South Yakutia. The UAV capacities were confirmed by comparing the aeromagnetic survey data with the available data obtained by ground magnetic exploration of the study area. By analysing magnetic fields, we established that the anomalies detected by the ground and aeromagnetic surveys were fully identical. Furthermore, a weak anomaly was discovered in the northeastern part of the study area (it was not reflected in the magnetic field from the ground survey data). Recalculation of the vertical gradient of the magnetic field shows that the anomaly is caused by a blind ore body. Its upper edge is located at a depth of $200-250 \mathrm{~m}$ from the day surface. In calculations for a data array without gradient intervals, a mean square error (MSE) amounts to $1.01 \mathrm{nT}$. An absolute error in the heights of the working and control flights did not exceed $1.5 \mathrm{~m}$. Both the preliminary and control measurements were performed very efficiently. Profiles for UAV surveys were spaced by $100 \mathrm{~m}$. A $1.0 \mathrm{~km}^{2}$ site was covered by one flight within approximately 20 minutes. The Geoskan-401 UAV is useful for obtaining orthophotos, topographic maps and 3D models of the surveyed territory as required for further studies consistent with the magnetic surveys. The aeromagnetic surveys were followed by trenching to verify the newly discovered anomalies. Based on the results of this experimental study, the forecast resources of the Sutam deposit should be increased by almost 250-350 million tons, i.e. plus $15 \%$ to the previously explored and approved reserves of the Sutam field.
\end{abstract}

KEYWORDS: magnetic exploration; iron-ore deposit; unmanned aeromagnetic survey complex; low altitude aeromagnetic survey; unmanned technology

FUNDING: The studies were supported by the Government of the Republic of Sakha (Yakutia) (2016-2020 Programme of Integrated Studies of the Territory), the Institute of the Earth's Crust SB RAS (Project 0381-2616-0001), and the Russian Foundation for Basic Research (Project No. 19-05-00062).

FOR CITATION: Syasko A.A., Grib N.N., Imaev V.S., Imaeva L.P., Kolodeznikov I.I., 2020. Detailed airborne geophysical survey of complexly dislocated strata in the Sutam terrane (Aldan shield) during studies of iron-ore deposits. Geodynamics \& Tectonophysics 11 (1), 141-150. doi:10.5800/GT-2020-11-1-0468 


\title{
ПРОВЕДЕНИЕ ДЕТАЛЬНЫХ АЭРОГЕОФИЗИЧЕСКИХ РАБОТ В СЛОЖНОДИСЛОЦИРОВАННЫХ КОМПЛЕКСАХ СУТАМСКОГО ТЕРРЕЙНА (АЛДАНСКИЙ ЩИТ) ПРИ ИЗУЧЕНИИ ЖЕЛЕЗОРУ ДНЫХ МЕСТОРОЖДЕНИЙ
}

\author{
А.А. Сясько ${ }^{1}$, Н.Н. Гриб르, В.С. Имаев ${ }^{3}$, Л.П. Имаева ${ }^{3}$, И.И. Колодезников ${ }^{4}$ \\ ${ }^{1} 000$ «Нерюнгри Геофизика», Нерюнгри, Россия \\ ${ }^{2}$ Технический институт (филиал) Северо-Восточного федерального университета им. М.К. Аммосова, Нерюн- \\ гри, Россия \\ ${ }^{3}$ Институт земной коры СО РАН, Иркутск, Россия \\ ${ }^{4}$ Академия наук Республики Саха (Якутия), Якутск, Россия
}

АннотАЦИЯ. Магниторазведка представляет собой наиболее информационный и экономичный метод при поиске и разведке железорудных месторождений. Избежать проблем с постановкой наземных методов на труднопроходимых и удаленных от инфраструктуры территориях, повысить скорость их изучения позволяют беспилотные технологии. Для оценки возможности применения беспилотной аэромагнитной съемки на железорудных объектах Якутии были выполнены опытно-методические работы на уже хорошо изученном ранее крупнейшем железорудном месторождении Южной Якутии с использованием беспилотного комплекса «Геоскан 401». Данный подход позволил установить работоспособность полетного комплекса, сопоставив имеющиеся данные наземных магниторазведочных работ с данными аэромагниторазведочных работ. Анализ магнитных полей показал полную идентичность полученных аномалий наземной и аэромагнитной съемки. Более того, на северо-востоке участка была выделена слабая аномалия, которая не отражена в магнитном поле наземной съемки. Пересчет вертикального градиента магнитного поля позволил определить, что аномалия обусловлена слепым рудным телом, верхняя кромка которого располагается на глубине 200-250 м от дневной поверхности. Среднеквадратическая погрешность, вычисленная для массива данных без градиентных интервалов, составила 1.01 нТл. Абсолютная погрешность высоты основного и контрольного полетов не превышает 1.5 м. По результатам рабочих и контрольных замеров отмечается высокая воспроизводимость измерений. За один полет по сети профилей с шагом 100 м был изучен участок площадью 1 км². Полетное время составило немногим более 20 мин. Дополнением работы с полетным комплексом «Геоскан 401» стала возможность съемки ортофотопланов, топопланов, трехмерных моделей местности - в зависимости от потребностей - последовательно с выполнением магниторазведочных работ. Согласно результатам аэромагниторазведочных работ и последующей заверке полученных новых аномалий горно-вскрышными работами в виде канав и траншей, прирост прогнозных ресурсов Сутамской площади составил примерно 250-350 млн т - 15 \% от уже опоискованных ранее и утвержденных запасов Сутамского месторождения.

КЛЮчЕВЫЕ СЛОВА: магниторазведка; железорудное месторождение; беспилотный аэромагнитный комплекс; низковысотная аэромагнитная съемка; беспилотные технологии

ФИНАНСИРОВАНИЕ: Исследования были выполнены при поддержке программы правительства Республики Саха (Якутия) по комплексному изучению территории на 2016-2020 гг., ИЗК СО РАН (проект № 0381-2616-0001), а также РФФИ (проект № 19-05-00062).

\section{1. ВВЕДЕНИЕ}

При поисках и разведке железных руд геофизические методы анализа являются главными, наиболее информационными и экономичными. Традиционными вариантами магниторазведки являются пешеходная съемка и аэромагниторазведка. Наращивание и расширение минерально-сырьевой базы РФ в настоящее время в основном связаны с поисково-оценочными работами в труднодоступных регионах, к которым относятся и железорудные объекты Якутии. Для таких объектов характерны сложные физико-географические условия, что затрудняет, замедляет и удорожает пешеходную съемку. Выполнение классической пилотируемой магниторазведки в этих районах также весьма затруднено из-за сильнопересеченного рельефа и отсутствия поблизости аэропортов.
Избежать проблем с постановкой наземных методов на труднопроходимых и удаленных от инфраструктуры территориях, повысить скорость их изучения позволяют беспилотные технологии. Перспективы крупномасштабных низковысотных съемок стали очевидны в конце прошлого века [Parshin, 2015, 2016; Macnae, 1995], однако до настоящего времени, несмотря на развитие рынка беспилотных летательных аппаратов (БПЛА), в практике отечественной геологической деятельности такие технологии не получили широкого распространения [Parshin, 2015; Korotkov et al., 2014].

Современную базу приповерхностных аэромагнитных исследований с применением БПЛА составляют аппараты, специально разработанные для аэромагнитных съемок, а также летательные аппараты, используемые для других гражданских целей: GeoSurvII (Канада), 
Venturer UAV (Канада), CH-3UAV (Китай), Radai's Terrain Scout UAV (Финляндия), GEM Systems Monarch (Канада), БАВК (беспилотный аэромагнитный комплекс) на базе БПЛА «Геоскан 201» (Россия) [GeoSurvII, 2019; Li et al., 2011; Martin et al., 2015; Pirttijärvi, 2015; Tezkan et al., 2019; Wood et al., 2016; Semenova, Tsirel, 2016].

\section{2. ТЕКТОНИЧЕСКОЕ ПОЛОЖЕНИЕ СУТАМСКОГО ЖЕЛЕЗОРУДНОГО МЕСТОРОЖДЕНИЯ}

Сутамская металлогеническая зона располагается на юге Центрально-Алданского гранулит-ортогнейсового составного террейна в пределах Сутамского блока, сложенного гнейсами с возрастом 2.5-3.0 млрд лет, метаморфизованными в условиях гранулитовой фации высоких давлений. Первые Fe-рудопроявления здесь были обнаружены в 1851 г. Якутской экспедицией Географического общества.

Олимпийское месторождение локализовано в сеймской свите нижнего архея. Структура рудного поля месторождения рассматривается как сложная синклиналь. Рудные тела месторождения сложены среднезернистыми гиперстен-магнетитовыми кварцитами полосчатой, грубополосчатой и массивной текстуры. По простиранию они иногда фациально переходят в магнетитгиперстеновые кристаллические сланцы. Местами полосчатость в рудной залежи обусловлена чередованием магнетитовых кварцитов и богатых магнетитовых руд. Изредка в магнетитовых кварцитах наблюдаются маломощные (до 30 см) линзы апатитмагнетитового состава. Иногда богатые магнетитовые и апатит-магнетитовые руды слагают мелкие тела неправильной формы, секущие метаморфическую полосчатость пород, но локализованные в пределах пластов магнетитовых кварцитов [Nikitin, Kolodeznikov, 2017; Parfenov, Kuzmin, 2001].

Олимпийское железорудное месторождение (рис. 1) вытянуто на 11 км при ширине 3-4 км. В районе месторождения различаются две группы горных пород. Первая представлена магнетит-гиперстеновыми и магнетитдвупироксеновыми гнейсами с прослоями амфиболдвупироксеновых и магнетит-двупироксен-плагиоклазовых сланцев. Породы слагают ядро антиформной складки. Железорудный горизонт, состоящий из магнетитовых и гиперстен-магнетитовых кварцитов, приурочен
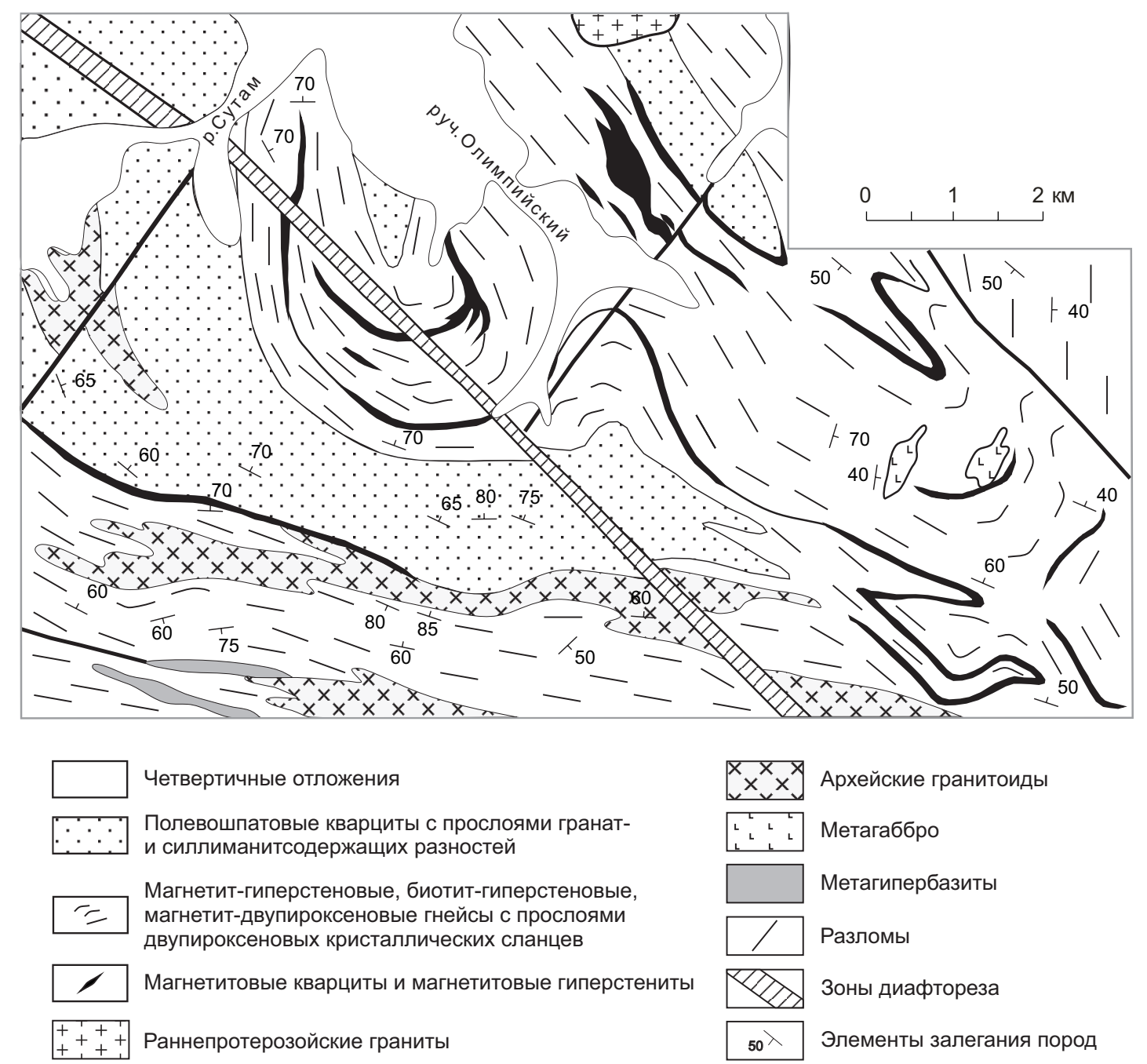

Рис. 1. Схема геологического строения железорудного месторождения Олимпийское (по [Parfenov, Kuzmin, 2001]). Fig. 1. Schematic geological map of the Olimpiiskoe iron-ore deposit (after [Parfenov, Kuzmin, 2001]). 
к внешней части антиформы. Вторая группа горных пород, слагающая ядро синформы, представлена полевошпатовыми кварцитами с прослоями гранат- и силлиманитсодержащих разностей. Отмечаются прослои диопсидовых пород и кальцифиров. С этой группой связан второй железорудный горизонт, который сложен магнетитовыми гиперстенитами и гранат-магнетитовыми гиперстенитами.

В пределах железорудных горизонтов выделяется 11 залежей линзовидной формы протяженностью 0.54.0 км и мощностью от 20 до 200 м. Залежи сложены средне- и крупнозернистыми полосчатыми гиперстенмагнетитовыми кварцитами. Содержание Fe-магнетитового варьируется от 25.30 до $36.98 \%$, S - от 0.08 до $0.13 \%$. Отмечаются единичные согласные линзы богатых апатит-магнетитовых руд мощностью до 30 см, в которых содержание Fe-магнетитового компонента составляет $61 \%, \mathrm{P}_{2} \mathrm{O}_{5}-4.11 \%$.

По геофизическим данным ресурсы Fе руд Олимпийского месторождения до глубины 300 м оцениваются в 500-900 млн т, до глубины 500 м - в 900-1500 млн т.

\section{3. МЕТОДЫ ПРОВЕДЕНИЯ ЭКСПЕРИМЕНТОВ И ОБОРУДОВАНИЕ}

Первые аэромагниторазведочные работы с использованием беспилотных летательных аппаратов в Якутии нами были выполнены на уже хорошо изученном ранее объекте - крупнейшем железорудном месторождении Южной Якутии [Syasko, 2019]. Следует отметить, что в 2015 г. на этом месторождении нами были выполнены традиционные наземные магниторазведочные работы, что позволяло достоверно установить работоспособность полетного комплекса, сопоставив имеющиеся данные наземных магниторазведочных работ с данными аэромагниторазведочных работ.

Система с вертикальным взлетом и посадкой «Геоскан 401» обладает высокой маневренностью, способностью вести съемку на самых малых высотах и зависать в заданной точке. Законченное решение для аэрофотосъемки включает фотокамеру Sony RX1, геодезический ГНСС приемник Торсоп и имеет гарантию 1 год/80 полетов. Его характеристики следующие: продолжительность полета до 60 мин, максимальная протяженность маршрута 24 км, площадь съемки за 1 полет

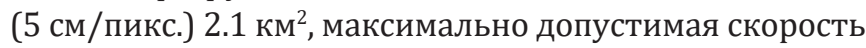
ветра до 10 м/с, скорость полета 0-50 км/ч, максимальная взлетная масса 9.3 кг, максимальная масса полезной нагрузки 2.5 кг.

Проведение профилей магниторазведочных работ было выполнено с помощью GPS-привязки. На борту полетного комплекса «Геоскан 401» был дополнительно размещен бортовой двухчастотный (L1, L2) двухсистемный (GPS/ГЛOНACC) геодезический приемник, позволяющий получать результаты с точностью 5-10 см без необходимости выполнения планово-высотной подготовки. Используемый при работах магнитометр также был оснащен встроенным GPS-приемником, позволяющим осуществить точную привязку каждой точки отсчета. Частота снятия отсчетов GPS-приемника в магнитометре - 10 отсчетов в секунду. Таким образом, при рабочей скорости полетного комплекса 36 км/ч привязка выполняется на каждом метре профиля [Geoskan 401, 2019].

В целом, проведенные полевые работы по магниторазведке соответствуют требованиям [Magnetic Exploration Guide..., 1981; Guidelines, 2018]. Магнитометр производства Geoscan, его основные технические характеристики: диапазон измерения модуля магнитной индукции 20000-120000 нТл с погрешностью отсчитывания 0.001 нТл, предел основной систематической погрешности измерения модуля магнитной индукции во всем диапазоне не более 0.2 нТл, предел средней квадратической погрешности при измерении магнитной индукции в диапазоне от 30000 до 102000 нТл не превышает 0.005 нТл, в диапазоне от 20000 до 30000 нТл не превышает 0.01 нТл. Среднеквадратичный уровень шума не более 0.01 нТл [Magnetometric Complex..., 2019].

Следует отметить техническое решение, воплощенное в конструкции магнитометра Geoscan - частота снятия значений напряженности полного вектора магнитного поля у магнитометра - 1000 Гц, 1000 отсчетов в секунду. Интегрированный GPS-приемник фиксирует 10 отсчетов (координат X, Y и Z) в секунду. Таким образом, на одну координатную точку приходится 100 отсчетов магнитометра. В итоговую таблицу записываются значения координат точки отсчета и усредненные на интервале 0.1 с отсчеты значений магнитного поля. Использование подобного подхода позволяет обеспечить высокую степень воспроизводимости измерений.

\section{4. ОБСУЖДЕНИЕ РЕЗУЛЬТАТОВ}

В качестве примера на рис. 2 приведен фрагмент аэромагнитного профиля опытно-методических работ с данными контрольных замеров. График 3 на рис. 2 демонстрирует диапазон изменения погрешности измерения. Очень хорошо видно, что максимальная погрешность измерений равна \pm 1 нТл. Абсолютная погрешность высоты основного и контрольного полетов не превышает 1.5 м на рис. 1. За один полет по сети профилей с шагом 100 м был изучен участок площадью 1 км². Полетное время составило немногим более 20 мин.

Для сравнения - на изучение этой же площади наземными магниторазведочными работами в 2015 г. потребовался бы труд двух бригад - топографической, для подготовки сети профилей, и геофизической - для наземных магниторазведочных работ, в течение более одного месяца.

На рис. 2 и рис. 3 приведены аномальные магнитные поля, построенные по данным наземной магниторазведки 2015 г. и опытно-методических полетов комплекса «Геоскан 401» с квантовым магнитометром в 2017 г.

Анализ полей показал полную идентичность полученных аномалий. Более того, на северо-востоке участка (самый дальний угол трехмерного изображения) в 2015 г.была выделена слабая аномалия. Буровые работы, 


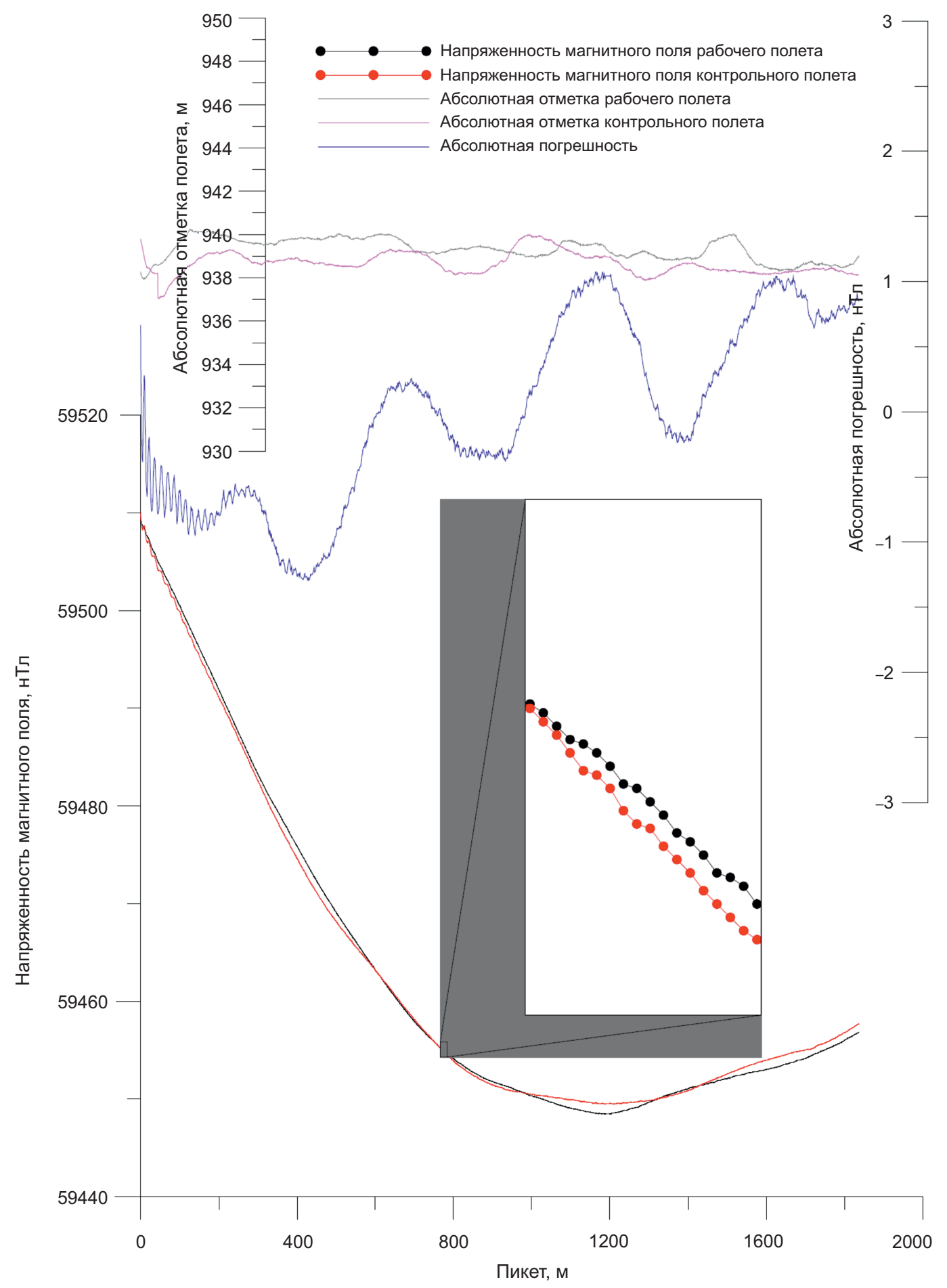

Рис. 2. Фрагмент аэромагнитного профиля опытно-методических работ с данными рабочих и контрольных замеров.

Fig. 2. Fragment of an aeromagnetic profile.

выполненные на площади этой аномалии, результатов не дали. Если взглянуть на аномальное магнитное поле, построенное по данным аэромагниторазведки, можно увидеть, что относительная интенсивность этой аномалии увеличилась по сравнению с аномалией наземной магниторазведки. Пересчет вертикального градиента магнитного поля позволил определить, что аномалия обусловлена слепым рудным телом, верхняя кромка которого располагается на глубине 200-250 м от дневной поверхности.

Наглядной иллюстрацией сказанного служит график, приведенный на рис. 3. На графике 1 отображены аномальные магнитные поля по данным наземной магниторазведки, на графике 2 - аэромагниторазведки. Отсчеты аэромагниторазведки расположены настолько плотно, что с трудом различаются даже на 


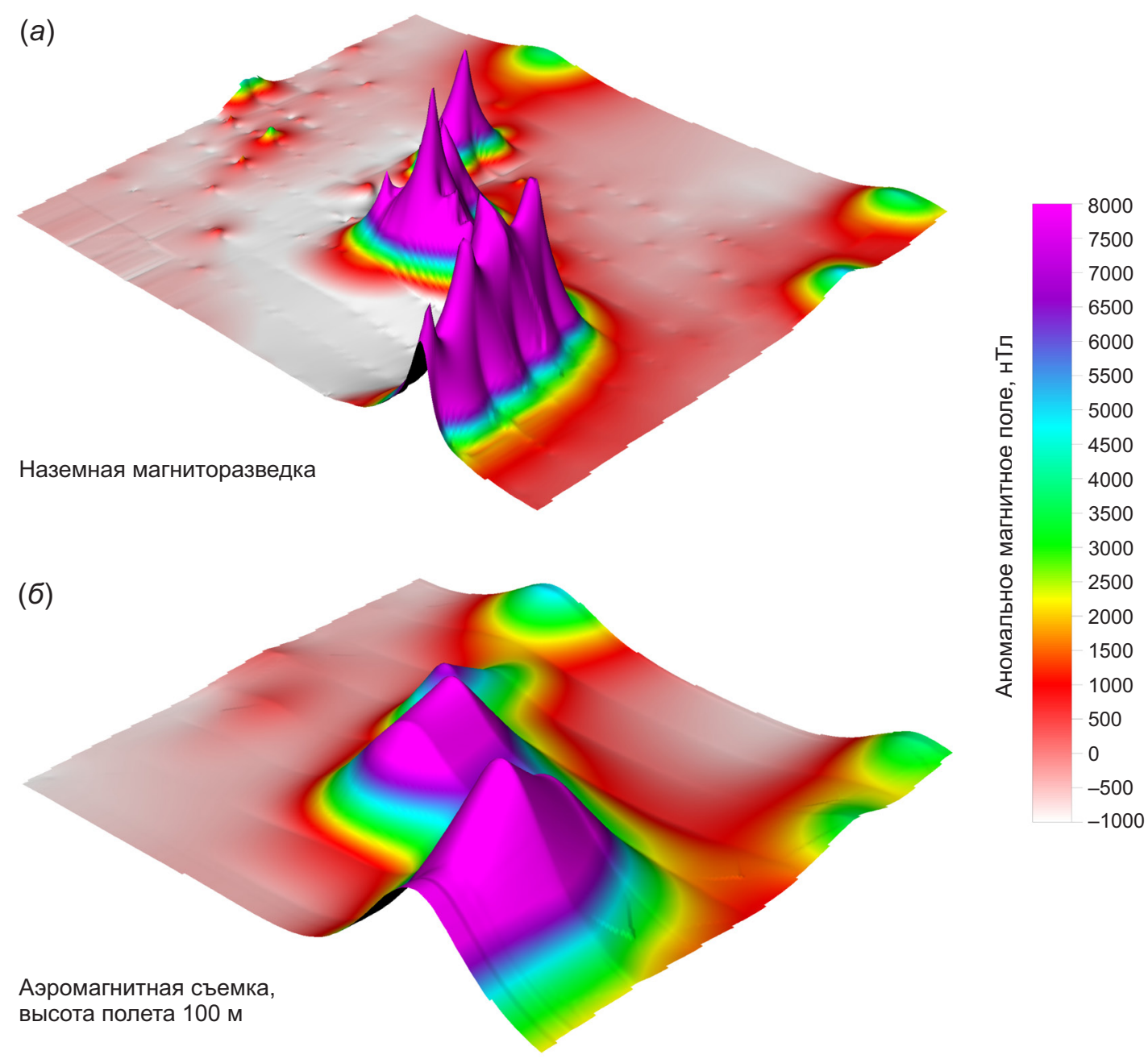

Рис. 3. Аномальное магнитное поле по данным наземной магниторазведки ( $a$ ) и по данным аэромагниторазведки (б), высота полета $100 \mathrm{M}$.

Fig. 3. Anomalous magnetic field from ground-based magnetic exploration ( $a$ ) and aeromagnetic survey data (б). Flight height $100 \mathrm{~m}$.

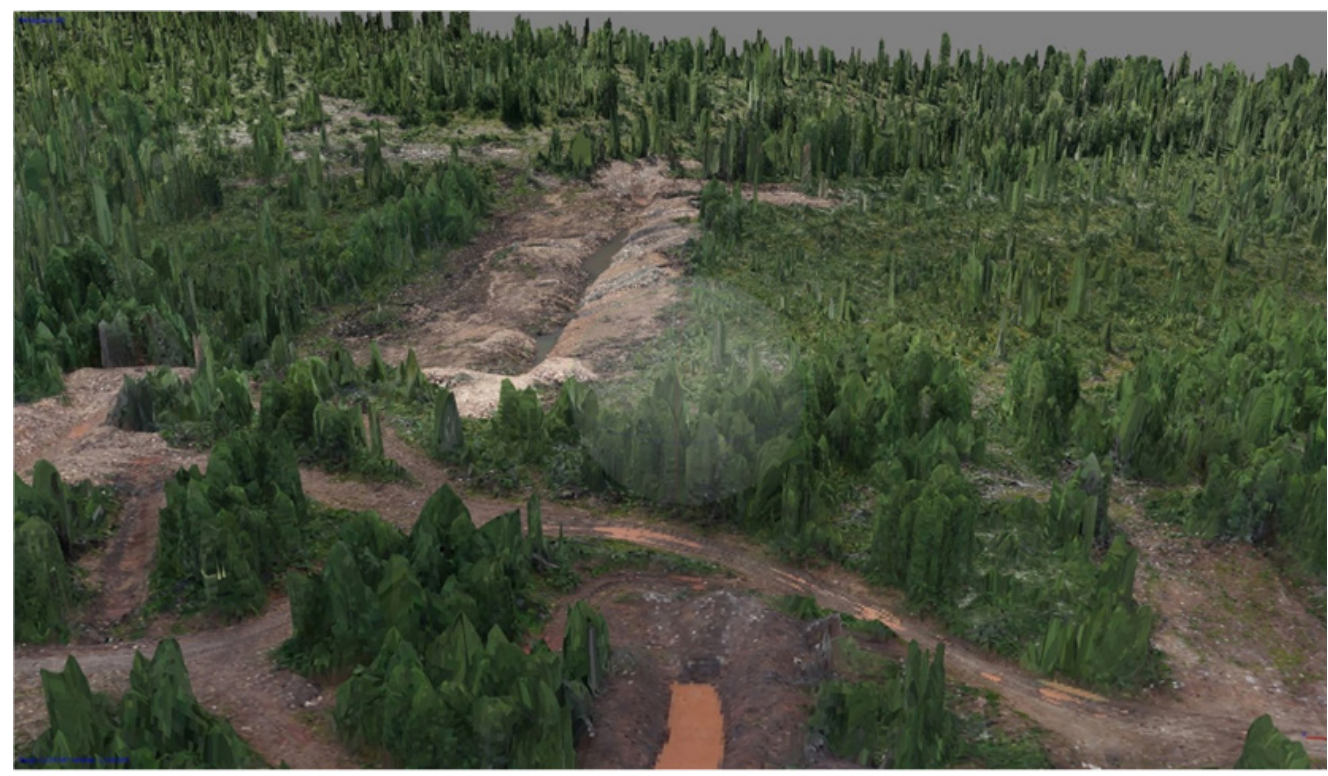

Рис. 4. Фрагмент рабочего окна программы Agisoft Geoscan Pro 1.5.1.

Fig. 4. Fragment of Agisoft Geoscan Pro 1.5.1 window. 
увеличенном фрагменте графика. На этом же фрагменте очень хорошо видно, насколько плавнее изменяется градиент поля на графике.

Может возникнуть вопрос об отсутствии высокочастотных аномалий на графике, построенном по данным аэромагниторазведки. Во-первых, стоит рассмотреть природу этих аномалий. Участок работ в буквальном смысле завален валунами магнетита, именно они и обусловливают наличие этого высокочастотного шума приповерхностных аномалий. Во-вторых, высота полета при производстве опытно-методических работ была задана равной 100 м из соображений безопасности. При необходимости высоту можно снизить, что позволит более контрастно регистрировать аномалии малых амплитуд.

Необходимо отметить еще один немаловажный аспект - воспроизводимость измерений, проще говоря контроль. Результаты рабочих и контрольных замеров представлены в виде графиков 4 и 5 (см. рис. 2).

Рабочие измерения отображены на графике 4, контрольные - на графике 5 (см. рис. 2). Погрешность измерений настолько мала, что разницу в замерах можно увидеть только на выноске-увеличителе. Среднеквадратическая погрешность, вычисленная для массива данных без градиентных интервалов, составила 1.01 нТл.

При работе с полетным комплексом «Геоскан 401» появилась возможность съемки ортофотопланов, топопланов, трехмерных моделей местности - в зависимости от потребностей - последовательно с выполнением магниторазведочных работ. На рис. 4 приведен фрагмент плотного облака точек программы Agisoft Photoscan Pro 1.5.1, на котором для примера отображена одна из разведочных выработок на участке работ [Agisoft Metashape..., 2019].

\section{5. РЕЗУЛЬТАТЫ РАБОТ}

На рис. 5 приведен план аномального магнитного поля участка работ. На северо-западе участка нами были выделены две аномалии, не обнаруженные предшественниками. Следует пояснить еще раз, что значит «не обнаруженные предшественниками». При производстве предшествующих работ геофизики выполняли только наземную съемку, или аэромагнитку, но по очень редкой сети профилей - из-за высокой стоимости производства работ. Наземная съемка на некоторых площадях месторождения была физически просто невозможна - вследствие тотальной заболоченности участка. Именно из-за полной непроходимости участок на северо-западе месторождения не был изучен детальными поисковыми работами.

Совмещение плана аномального магнитного поля и карты месторождения с вынесенными рудными телами показало достаточно хорошее совпадение морфологии рудных тел в плане с положительными аномалиями магнитного поля (рис. 6), что в дальнейшем использовалось

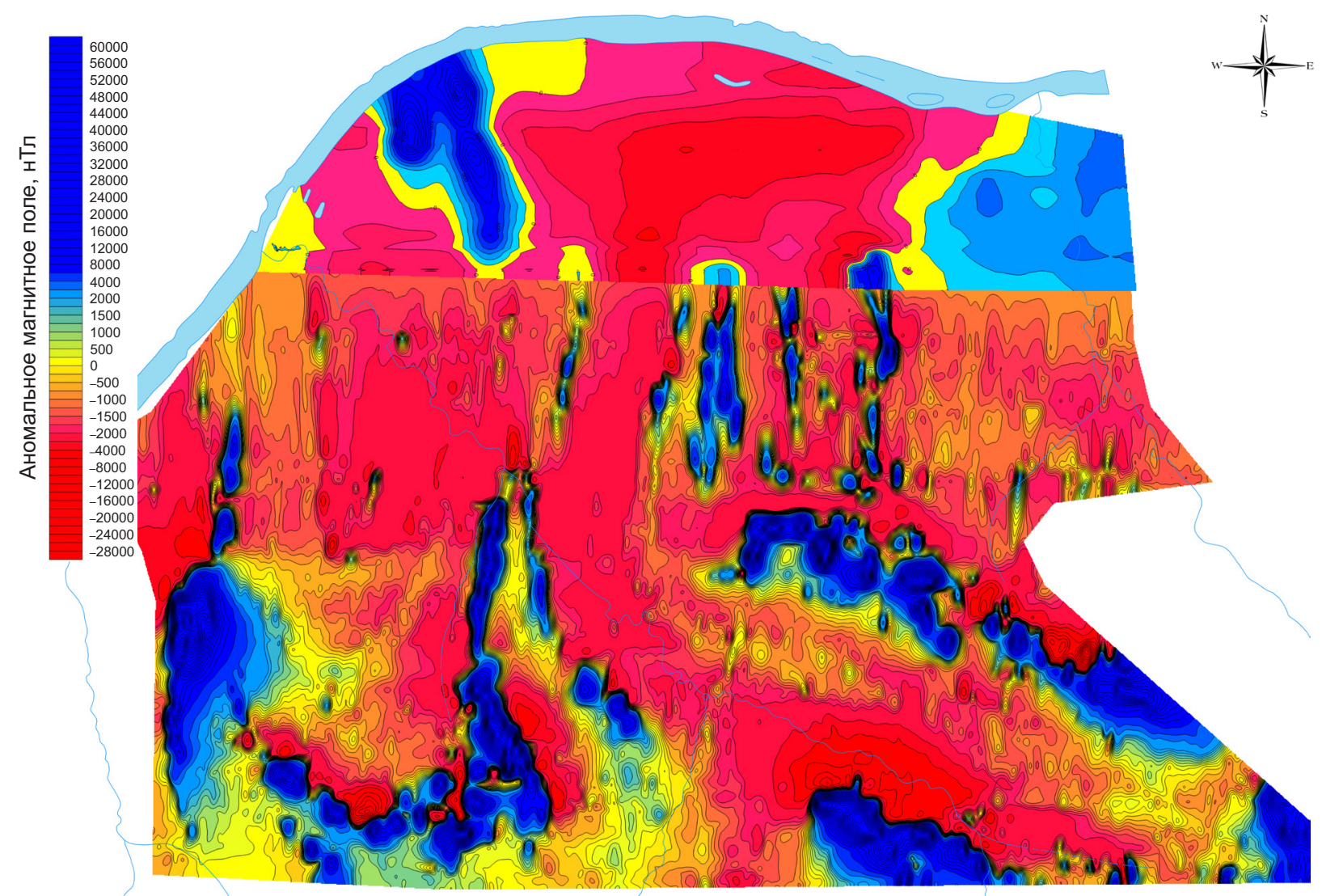

Рис. 5. План изолиний аномального магнитного поля участка работ месторождения «Сутам».

Fig. 5. Isolines of the anomalous magnetic field at the Sutam deposit. 


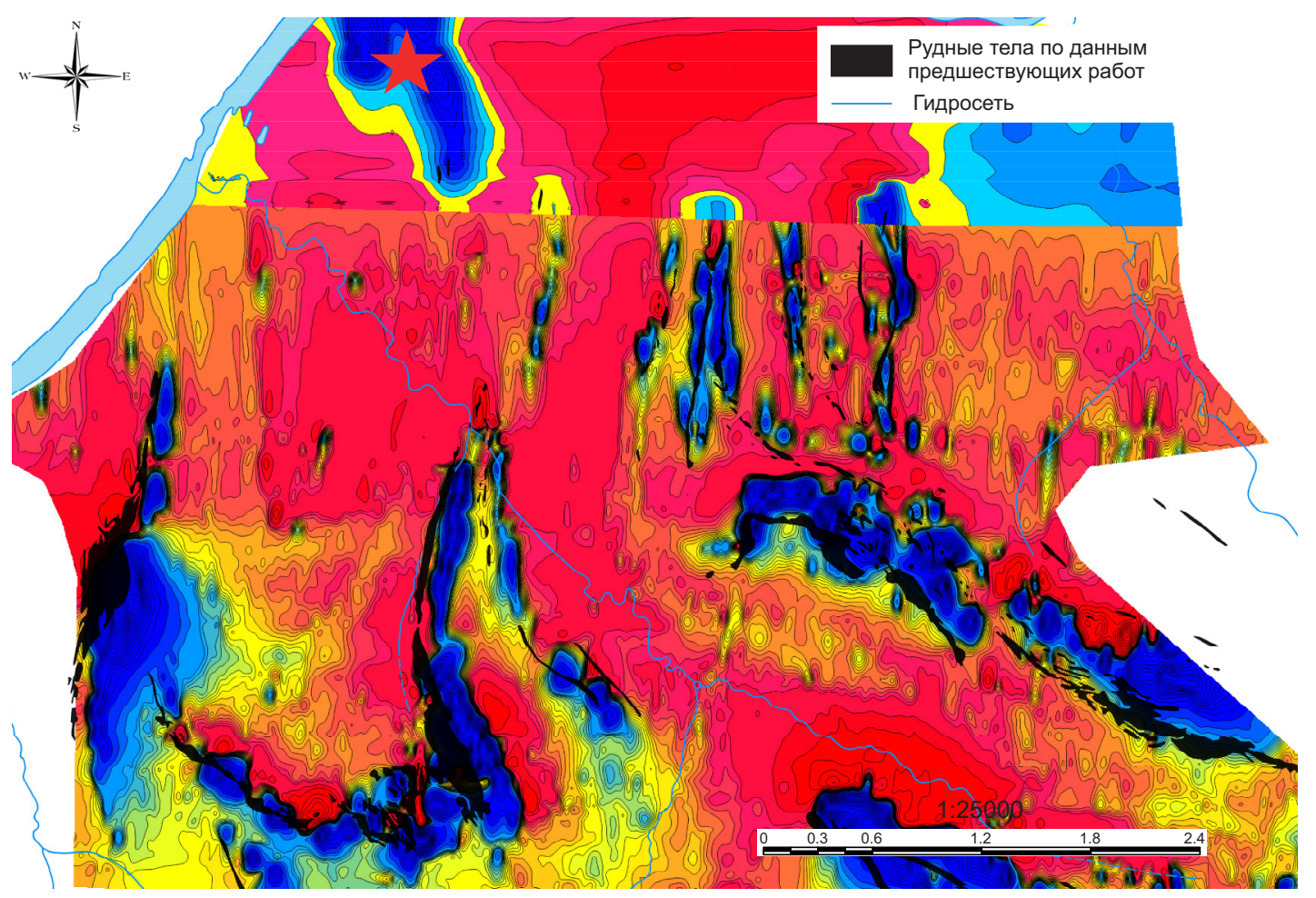

Рис. 6. Совмещение плана аномального магнитного поля по данным работ 2017 г. и рудных тел, картированных по данным предшествующих работ. Звездочкой показано местоположение новых рудных тел, закартированных при помощи беспилотного комплекса.

Fig. 6. The anomalous magnetic field based on the data obtained in 2017, and the ore bodies mapped in the previous surveys. Asterisk - locations of newly discovered ore bodies that were mapped using the data from the Geoscan 401 UAV.

для интепретации полученного материала и выделения новых перспективных площадок обнаружения железосодержащих жил и рудных тел.

\section{6. ЗАКЛЮЧЕНИЕ}

Таким образом, несмотря на то, что в настоящее время беспилотные технологии еще не заняли в России значимой доли рынка, полученные результаты свидетельствуют о возможности замещения существенной доли как наземных работ, так и классических аэросъемок беспилотными технологиями.

Проведенные научно-исследовательские работы показали высокую эффективность и производительность магнитной съемки. Высокая точность произведенных измерений изолиний аномального магнитного поля

\section{8. ЛИТЕРАТУРА/REFERENCES}

Agisoft Metashape (PhotoScan) Pro 1.5.1, 2019. Available from: https://легион.net/agisoft-photoscan-pro-rus/ (Last accessed April 17, 2019).

Geoskan 401, 2019. Technical Specification (in Russian) [Геоскан 401. Технические характеристики]. Available from: http://avia.pro/blog/geoskan-401-tehnicheskieharakteristiki-foto (Last accessed May 7, 2019).

GeoSurvII, 2019. Available from: http://www.GeoSurvII. carleton.ca/mae/wp-content/uploads/UAV-Projects (Last accessed May 7, 2019). позволяет оперативно получать, обрабатывать и коррелировать полученные материалы с результатами наземных горно-разведочных работ.

Рассмотренные выше материалы опытно-методических работ свидетельствуют о возможности получения данных аэромагниторазведки высокого качества и детальности беспилотными методами на высоте 100 м над рельефом дневной поверхности.

\section{7. БЛАГОДАРНОСТИ}

Данные исследования были выполнены при поддержке программы правительства Республики Саха (Якутия) по комплексному изучению территории на 2016-2020 гг., ИЗК СО РАН (проект № 0381-2616-0001), а также РФФИ (проект № 19-05-00062).

Guidelines for Low-Altitude Aeromagnetic Survey, 2018. Moscow, 32 p. (in Russian) [Методические рекомендации по выполнению маловысотной аэромагнитной съемки. М., 2018. 32 с.].

Korotkov V.V., Glinskiy N.A., Kirsanov V.N., Kleper N.B., Kuznetsova A.V., Tsirel' V.S., 2014. Measurements using unmanned aerial vehicles - a new stage of development of domestic aerogeophysics. Rossiiskii Geofizicheskii Zhurnal (Russian Geophysical Journal) (53-54), 122-125 (in Russian) [Коротков В.В., Глинский Н.А., Кирсанов В.Н., Клепер Н.Б., Кузнецова А.В., Цирель В.С. Съемки с использованием 
беспилотных летательных аппаратов - новый этап развития отечественной аэрогеофизики // Российский геофизический журнал. 2014. № 53-54. C. 122-125].

Li X., Li Y., Meng X., Zhang B., Guo Z., Zhu L., Qiao Y., 2011. A three-component aeromagnetic compensation for UAV Platform. In: International Workshop on Gravity, Electrical \& Magnetic Methods and Their Applications (Beijing, China, October 10-13, 2011). Institution of Remote Sensing Application, Beijing, p. 66. https://doi.org/10. 1190/1.3659108.

Macnae J., 1995. Design specifications for a geophysical unmanned air vehicle assembly (GUAVAS). SEG Technical Program Expanded Abstracts 14, 375-376. https://doi. org/10.1190/1.1887449.

Magnetic Exploration Guide. Ground-Based Magnetic Survey, Aeromagnetic Survey, and Hydromagnetic Survey, 1981. Nedra, Leningrad, 263 p (in Russian) [Инструкция по магниторазведке. Наземная магнитная съемка, аэромагнитная съемка, гидромагнитная съемка. Л.: Недра, 1981. 263 с.].

Magnetometric Complex Geoscan, 2019 (in Russian) [Магнитометрический комплекс Геоскан. Available from: https://www.geoscan.aero.ru/services/aeromagnetic survey (Last accessed April 17, 2019).

Martin P.G., Payton O.D., Fardoulis J.S., Richards D.A., Scott T.B., 2015. The use of unmanned aerial systems for the mapping of legacy uranium mines. Journal of Environmental Radioactivity 143, 135-140. https://doi.org/10. 1016/j.jenvrad.2015.02.004.

Nikitin V.M., Kolodeznikov I.I., 2017. The role of iron ores of the Sutam region in the economic development of the eastern regions of South Yakutia and their characteristics. Nauka i Obrazovanie (Science and Education) (3), 6467 (in Russian) [Никитин В.М., Колодезников И.И. Роль железных руд Сутамского района в экономическом развитии востока Южной Якутии и их характеристики // Наука и образование. 2017. № 3. С. 64-67].

Parfenov L.M., Kuzmin M.I. (Eds), 2001. Tectonics, Geodynamics and Metallogeny of the Territory of the Republic of Sakha (Yakutia). Nauka/Interperiodika, Moscow, 571 p. (in Russian) [Тектоника, геодинамика и металлогения территории Республики Саха (Якутия) / Ред. Л.М. Парфенов, М.И. Кузьмин. М.: МАИК «Наука/Интерпериодика», 2001. 571 с.].

Parshin A.V., 2015. Prospects for using unmanned aerial vehicles in geological exploration of ore objects in the Baikal mountain region. Voprosy Estestvoznania (Problems of Natural Sciences) (2), 97-101 (in Russian) [Паршин A.B. Перспективы применения беспилотных летательных аппаратов при выполнении геологоразведочных работ на рудных объектах Байкальской горной области // Вопросы естествознания. 2015. № 2. С. 97-101].

Parshin A.V., 2016. Complex for Unmanned Aeromagnetic Survey. RF Patent. Application No. 2016129683. Priority 19.07.2016 (in Russian) [Паршин А.В. Комплекс для беспилотной аэромагниторазведки. Патент РФ. Заявка № 2016129683. Приоритет 19.07.2016].

Pirttijärvi M., 2015. Ryssänlampi magnetic survey using Radai UAV system and its comparison to airborne and ground magnetic data of GTK. Detailed Survey Report. Available from: http://tupa.gtk.fi/raportti/arkisto/30_2016.pdf (Last accessed May 7, 2019).

Semenova M.P., Tsirel V.S., 2016. Prospects for the development of unmanned airborne geophysics. Exploration and Protection of Subsoil (8), 34-39 (in Russian) [Семенова М.П., Цирель В.С. Перспективы развития беспилотной аэрогеофизики // Разведка и охрана недр. 2016. № 8. C. 34-39].

Syasko A.A., 2019. Application of the Geoscan 401 complex in aeromagnetic exploration (in Russian) [Сясько A.A. Применение комплекса Геоскан 401 в аэромагниторазведке]. Available from: https://www.geoscan.aero.ru/ blog/713 (Last accessed April 17, 2019).

Tezkan B., Bergers R., Stoll J.B., Munch U., 2019. Electromagnetic measurement method using unmanned aerial system: Research project AIDA. Available from: http:// www.geotechnologien.de/images/Documente/aida.pdf (Last accessed May 7, 2019).

Wood A., Cook I., Doyle B., Cunningham M., Samson C., 2016. Experimental aeromagnetic survey using an unmanned air system. The Leading Edge 35 (3), 270-273. https:// doi.org/10.1190/tle35030270.1.

\section{ANDREY A. SYASKO}

Candidate of Technical Sciences

LLC Neryungri Geophysics

41-2 Geologist Ave, Neryungri 678960, Russia

\section{NIKOLAI N. GRIB}

Doctor of Technical Sciences, Professor

Technical Institute (branch) of M.K. Ammosov North-Eastern Federal University 16 Kravchenko St, Neryungri 678960, Russia e-mail: grib@nfygu.ru

\section{АНДРЕЙ АЛЕКСАНДРОВИЧ СЯСЬКО}

K.T.H.

000 «Нерюнгри Геофизика»

678960, г. Нерюнгри, пр-т Геологов, 41, корп. 2, Россия

\section{НИКОЛАЙ НИКОЛАЕВИЧ ГРИБ}

докт. техн. наук, профессор

Технический институт (филиал) Северо-Восточного

федерального университета им. М.К. Аммосова 678960, г. Нерюнгри, ул. Кравченко, 16, Россия 


\section{VALERY S. IMAEV}

Doctor of Geology and Mineralogy, Chief Researcher Institute of the Earth's Crust, Siberian Branch of RAS 128 Lermontov St, Irkutsk 664033, Russia

e-mail: imaev@crust.ru

ORCID: 0000-0002-6510-0526

\section{LYUDMILA P. IMAEVA}

Candidate of Geology and Mineralogy, Senior Researcher Institute of the Earth's Crust, Siberian Branch of RAS 128 Lermontov St, Irkutsk 664033, Russia

e-mail: imaeva@crust.ru

ORCID: 0000-0002-8235-7112

\section{IGOR I. KOLODEZNIKOV}

Doctor of Geology and Mineralogy, Professor Academy of Sciences of the Republic of Sakha (Yakutia) 9 Lenin Ave, Yakusk 677007, Russia

\section{ВАЛЕРИЙ СУЛЕЙМАНОВИЧ ИМАЕВ}

докт. геол.-мин. наук, г.н.с.

Институт земной коры СО РАН

664033, г. Иркутск, ул. Лермонтова, 128, Россия

\section{ЛЮДМИЛА ПЕТРОВНА ИМАЕВА}

канд. геол.-мин. наук, с.н.с.

Институт земной коры СО РАН

664033, г. Иркутск, ул. Лермонтова, 128, Россия

\section{ИГОРЬ ИННОКЕНТЬЕВИЧ КОЛОДЕЗНИКОВ}

докт. геол.-мин. наук, профессор

Академия наук Республики Саха (Якутия)

677007, г. Якутск, пр-т Ленина, 9, Россия 